\title{
To Assess the Quality of Life (QOL) of Caregivers and Patients Suffering from Chronic Obstructive Pulmonary Disease (COPD)
}

\author{
Sanjeev Kumar ${ }^{1}$, Prithpal S Matreja ${ }^{2 *}$, Ashwani K Gupta ${ }^{2}$, Amandeep Singh² and Preeti Garg ${ }^{2}$ \\ ${ }^{1}$ Department of Pulmonary Medicine, Gian Sagar Medical College, Ram Nagar, Rajpura, Patiala, India \\ ${ }^{2}$ Department of Pharmacology, Gian Sagar Medical College, Ram Nagar, Rajpura, Patiala, India
}

\begin{abstract}
Rationale: Chronic Obstructive Pulmonary Disease (COPD) is associated with physical and psychological burdens. The impact of disease has been studied on patients but it also has a profound and pervasive effect on family and friends resulting in psychological strain, social isolation, relationship strains and financial strains from the added responsibilities of managing the patients. Few studies have found a significant burden on both caregivers and patients alike, but the data from the Indian setup in lacking. Hence, we designed this study to assess the Quality of Life (QOL) of caregivers and patients suffering from COPD.
\end{abstract}

Methods: A cross-sectional study was carried out with forty-six COPD patients and their primary caregivers. Patients were assessed with St. George's Respiratory Questionnaire (SGRQ), and WHO-QOL-Bref scores. The caregivers were divided into two groups. Group 1 volunteers were caregivers of patients recently diagnosed with COPD (Last 1 year), whereas Group 2 were caregivers of patients with COPD diagnosed more than 1 year back. The caregivers in both the groups were subjected to Zarit Burden Interview (ZBI) and WHO-QOL-Bref scores.

Results: 46 patients and caregivers were enrolled in the study. Majority of patients were over the age of 50 years (55.67 \pm 12.45 ), and $67 \%$ caregivers were females. Patients had poor QOL as per SGRQ. The caregivers in Group 1 had significantly lower $(p<0.05)$ burden as compared to Group 2 as evident by ZBI scores. The WHO-QOL-Bref scores in all the 4 domains were significantly higher in Group 1 which predicts a better quality of life.

Conclusion: COPD takes a toll not only on the patient but also the caregiver of the patients. The amount of burden increases as the disease progress with worsening quality of life.

\section{Introduction}

Chronic Obstructive Pulmonary Disease (COPD) affects approximately 12.1 million Americans and is the fourth leading cause of preventable death for both men and women in the US, with over 120,000 deaths reported in 2002 [1]. 200 million patients are reported to be suffering from COPD in India as per 2011 estimates and three-fourth of this population resides in Urban areas. The total cost of treatment is around 3.5 billion rupees. It is estimated that the number of patients will rise to 220 million and cost will rise to 4.8 billion rupees by 2016 [2]. It is an obstructive airway disease characterized by symptoms of dyspnoea, paroxysmal coughing, fatigue, and insomnia. There is no cure for the disease and treatment is primarily focused on symptom management, moreover there has been no new treatment approved for management of COPD in the past decade. COPD patients have to cope with multiple disease related symptoms and the side-effects of treatment $[1,3]$. In addition, COPD patients demonstrate high rates of psychological distress, more than those with other chronic medical conditions with a prevalence rates for depressive symptoms or major depression as high as $80 \%$, and elevated symptoms of anxiety exceeding $90 \%$ [1]. Anxiety can be provoked by common symptoms of COPD and can worsen symptoms leading to heightened anxiety and symptom exacerbation. Psychological distress has profound impact on QOL of patients [3].

COPD also has a profound and pervasive effect on family and friends resulting in psychological strain, social isolation, relationship strains and financial strains from added responsibilities of managing patients [3]. Caregiver is used to refer to unpaid relatives or friends of a disabled individual who help that individual with his or her activities of daily living. The words may be prefixed with "family" "spousal", "child", "parent", "young" or "adult" [4]. Burden of care indicates "the extent to which caregivers perceive their emotional or physical health, social life, and financial status suffering as a result of caring for their relative". Caregivers of COPD patients also have additional roles such as decision-making and managing finance and they also have to deal with patient attitudes and irritability [3,5].

The experience of a wife caregiver has been described as a mixture of anger, helplessness, guilt and isolation and was deemed to have lost freedom, because they had relinquished recreational and social activities. Persistent worry about the patients' health and symptoms was common, and frequently associated with fatigue and difficulty sleeping. Compared with wives of husbands without COPD, wives of COPD patients reported lower levels of life satisfaction [5].

Few studies have reported almost comparable compromised QOL of caregivers of patients suffering from COPD along with patients. The data pertaining to Indian setup is lacking, hence we designed this study to assess the quality of life of caregivers as well as patients suffering from chronic obstructive pulmonary disease (COPD).

*Corresponding author: Prithpal Singh Matreja, Assistant Professor, Department of Pharmacology, Gian Sagar Medical College and Hospital, Ramnagar, Patiala India, Tel: + 91-9855001847, +91-1762-507118; Fax: +91-1762-520024; E-mail: drpsmatreja@yahoo.co.in

Received April 25, 2012; Accepted May 21, 2012; Published May 26, 2012

Citation: Kumar S, Matreja PS, Gupta AK, Singh A Garg P (2012) To Assess the Quality of Life (QOL) of Caregivers and Patients Suffering from Chronic Obstructive Pulmonary Disease (COPD). J Aller Ther S2:003. doi:10.4172/2155-6121.S2-003

Copyright: @ 2012 Kumar S, et al. This is an open-access article distributed under the terms of the Creative Commons Attribution License, which permits unrestricted use, distribution, and reproduction in any medium, provided the original author and source are credited. 


\section{Aims and Objectives}

To assess the Quality of life (QOL) of patients suffering from chronic obstructive pulmonary disease (COPD) in Indian Population.

To assess the QOL of caregivers of patients suffering from COPD in Indian Population.

\section{Procedure}

This prospective, cross sectional study was conducted in patients and their caregivers visiting the Out Patient Department of Chest and Tuberculosis form October 2011 to January 2012. A total of 80 patients and their caregivers were screened for enrollment in the study. 18 patients came to the out-patient department without caregiver, 9 patients and 7 caregivers did not give their consent and hence were excluded for the study. 46 patients suffering from COPD along with their caregivers were enrolled in the study after they signed a written informed consent. The study was approved by Institutional Ethics Committee (IEC) and was conducted in accordance with GCP guidelines. The caregivers were divided based on their duration of illness into two groups. Group 1 had caregivers where the duration of illness of COPD of less than 1 year whereas the caregivers of group 2 had patients who were suffering from COPD for more than 1 year.

\section{Parameters}

1. Patients were subjected to St. George Respiratory Questionnaire (SGRQ) [6-8] and WHO - Quality of life (WHO-QOL Bref) Questionnaire [9-12].

2. Caregivers were subjected to Zarit Burden Interview (ZBI) $[13,14]$ and WHO - Quality of life (WHO-QOL Bref) Questionnaire

St. george respiratory questionnaire: Patients were administered St. George Respiratory Questionnaire, it is designed to measure health impairment in patients suffering from asthma and COPD. It has two parts, part 1 produces symptom score (effect of respiratory symptoms, their frequency and severity), and part 2 the activity (activities that cause/ are limited by breathlessness) and impacts (social and psychological disturbances) score. It is designed for self administration and should be completed in a quiet area, free from distraction and elicits the patient's opinion. Scores range from 0 to 100 percent, where 100 represents worst possible health status and 0 indicates best possible health status [6-8].

The WHO QOL-Bref: This is a 26-item self-administered generic questionnaire, a short version of WHOQOL -100 scale [9]. It can be analyzed from perspective of either six domains (physical health, psychological health, level of independence, social relationships, environment, \& spiritual) or four domains (physical health, psychological health, social relations, and environment).

Modification of WHO QOL-Bref for impression of caregivers: In order to produce the version of WHOQOL-Bref with which family caregivers rated their impression of the patients' QOL, we used the method of Sainfort et al. [10], by giving a new direction to each item. By this modification, caregiver could rate patient as an observer. The modification of WHO QOL-Bref was thus minimal $[10,11]$. The internal consistency of WHO QOL-Bref, as assessed by Cronbach's alpha coefficient for responses of all caregivers was high ( 0.89 for the original WHO QOL-Bref, and 0.93 for the caregiver impression version) [11]. Four domains are defined for WHO QOLBref, based on its 26 items: domain 1, physical health, is on activities of daily living, dependence on medicinal substances and medical aids, energy and fatigue, mobility, pain and discomfort, sleep and rest, and work capacity. Domain 2, psychological health, includes bodily image and appearance, negative feelings, positive feelings, self-esteem, spirituality, religion, personal beliefs, thinking, learning, memory, and concentration. Domain 3, social relationships, covers personal relationships, social support, and sexual activity. Domain 4, environment, assesses financial resources, freedom, physical safety and security, health and social care (accessibility and quality), home environment, opportunities for acquiring new information and skills, participation in and opportunities for recreation and leisure activities, physical environment (pollution, noise, traffic, and climate), and transport. The raw score of each domain was then transferred to standardized score of 0 to 100 , in order to maintain uniformity in scores. Higher scores mean better quality of life of patients. The QOL index of each domain and their associations with demographic factors were assessed $[9,12]$.

Zarit Burden Interview: Caregiver's were administered Zarit Burden Interview. The ZBI scale was developed to measure burden among family caregivers of persons and consists of 22 questions with answer varying from $0=$ never to $4=$ nearly always. The score values range from 0-21, 21-40, 41-60 and 61-88, a low score indicates little or no burden whereas a high score indicates severe burden $[13,14]$.

\section{Results}

46 patients and their caregivers were enrolled in the study and completed the questionnaires.

\section{Patients}

All the patients completed both questionnaires. Most of the patients were above the age of 50 years and were males. The characteristics of patients are described in Table 1 and 2.The patients had lower WHOQOL Bref scores in all domains except in Domain II and III where the score was significantly lower as compared to caregivers (Figure 1).

\section{Caregivers}

46 caregivers participated in the study and completed both $\mathrm{ZBI}$ and WHO-QOL Bref Questionnaire. The ZBI characteristics of the caregivers are shown in Table 2 and 3

The caregivers were divided into two groups based on the duration of disease. Group 1 had caregivers whose patients were suffering from COPD from less than 1 year. Whereas Group 2 had caregivers who had patients diagnosed with COPD more than 1 year back. Group 1 had a significantly lower ZBI scores as compared to Group 2. The

\begin{tabular}{|l|l|}
\hline Characteristic & $(\mathrm{n}=46)$ \\
\hline Age (Mean \pm SD) & $55.67 \pm 12.45$ \\
\hline Sex (M:F) & $34: 12$ \\
\hline SGRQ Scores & \\
\hline Symptom Score (Mean \pm SD) & $57.36 \pm 11.95$ \\
\hline Activity Score (Mean \pm SD) & $36.33 \pm 11.44$ \\
\hline Impact Score (Mean \pm SD) & $36.93 \pm 7.39$ \\
\hline Total Score (Mean \pm SD) & $40.14 \pm 6.35$ \\
\hline WHO-QOL Bref Score & \\
\hline Domain I (4-20) (Mean \pm SD) & $12.17 \pm 1.45$ \\
\hline Domain II (4-20) Mean \pm SD) & $10.78 \pm 1.77$ \\
\hline Domain III (4-20) (Mean \pm SD) & $10.91 \pm 1.41$ \\
\hline Domain IV (4-20) (Mean \pm SD) & $11.96 \pm 1.98$ \\
\hline
\end{tabular}

Table 1: Characteristic of patients. 
Citation: Kumar S, Matreja PS, Gupta AK, Singh A Garg P (2012) To Assess the Quality of Life (QOL) of Caregivers and Patients Suffering from Chronic Obstructive Pulmonary Disease (COPD). J Aller Ther S2:003. doi:10.4172/2155-6121.S2-003

\begin{tabular}{|l|l|l|l|}
\hline \multicolumn{1}{|c|}{ Characteristic } & \multicolumn{1}{|c|}{$\begin{array}{c}\text { Patients } \\
(\mathbf{n = 4 6 )}\end{array}$} & $\begin{array}{c}\text { Caregivers } \\
(\mathbf{n = 4 6 )}\end{array}$ & p value \\
\hline Age (Mean \pm SD) & $55.67 \pm 12.45$ & $38.74 \pm 14.66$ & $\mathrm{p}<0.05^{*}$ \\
\hline Sex (M:F) & $34: 12$ & $24: 22$ & $\mathrm{p}>0.05 \#$ \\
\hline WHO-QOL Bref Score & & & \\
\hline Domain I (4-20) (Mean \pm SD) & $12.17 \pm 1.45$ & $12.11 \pm 1.71$ & $\mathrm{p}>0.05^{*} \infty$ \\
\hline Domain II (4-20) Mean \pm SD) & $10.78 \pm 1.77$ & $11.67 \pm 2.24$ & $\mathrm{p}<0.05^{*} \infty$ \\
\hline Domain III (4-20) (Mean \pm SD) & $10.91 \pm 1.41$ & $12.85 \pm 1.96$ & $\mathrm{p}<0.05^{*} \infty$ \\
\hline Domain IV (4-20) (Mean \pm SD) & $11.96 \pm 1.98$ & $12 \pm 1.28$ & $\mathrm{p}>0.05^{*} \infty$ \\
\hline
\end{tabular}

*Using Unpaired Student 't' Test

\#Using Chi-Square Test

$\infty$ Using Mann Whitney U Test

Table 2: Comparison between caregivers and patients

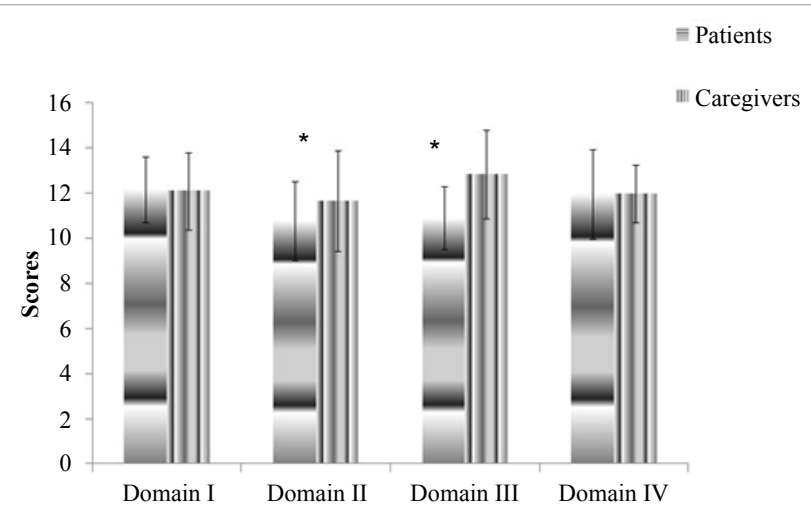

${ }^{*} \mathrm{p}<0.05$ as compared to other group

Figure 1: WHO-QOL Bref Scores.

\begin{tabular}{|l|l|l|l|}
\hline Characteristic & $\begin{array}{l}\text { Group 1 } \\
(\mathbf{n}=\mathbf{1 6})\end{array}$ & $\begin{array}{l}\text { Group 2 } \\
\mathbf{( n = 3 0 )}\end{array}$ & p value \\
\hline Age (Mean \pm SD) & $38.25 \pm 14.38$ & $39 \pm 15.04$ & $\mathrm{p}>0.05^{\star}$ \\
\hline Sex (M:F) & $7: 9$ & $17: 13$ & $\mathrm{p}>0.05 \#$ \\
\hline Relation (Spouse:Sibling:Other) & $7: 6: 3$ & $10: 14: 6$ & $\mathrm{p}>0.05 \#$ \\
\hline ZBI Score (Mean \pm SD) & $15.75 \pm 5.35$ & $37.7 \pm 14.44$ & $\mathrm{p}<0.05^{\star} \infty$ \\
\hline ZBI Ratio(0-20:21-40:41-60:61-84) & $13: 3: 0: 0$ & $0: 20: 8: 2$ & \\
\hline WHO-QOL Bref Score & & & \\
\hline Domain I (4-20) (Mean \pm SD) & $12.3 \pm 1.77$ & $11.75 \pm 1.69$ & $\mathrm{p}>0.05^{*} \infty$ \\
\hline Domain II (4-20) Mean \pm SD) & $11.97 \pm 2.22$ & $11.13 \pm 2.25$ & $\mathrm{p}>0.05^{*} \infty$ \\
\hline Domain III (4-20) (Mean \pm SD) & $13.33 \pm 1.79$ & $11.94 \pm 1.98$ & $\mathrm{p}<0.05^{*} \infty$ \\
\hline Domain IV (4-20) (Mean \pm SD) & $12.07 \pm 1.34$ & $11.88 \pm 1.20$ & $\mathrm{p}>0.05^{\star} \infty$ \\
\hline
\end{tabular}

*Using Unpaired Student 't' Test

\#Using Chi-Square Test

œUsing Mann Whitney U Test

Table 3: Comparison between caregivers.

WHO QOL-Bref score was higher in group 1 and significantly higher in Domain III in group 1 as compared to group 2.

\section{Discussion}

COPD not only takes a toll on patient's health but also affects the quality of life of the patients, and along with patients the caregivers also experiences a psychological and social burden. This crosssectional study done on 46 patients suffering from COPD and their caregivers showed that the disease affected quality of life of patients as well as caregivers of patients. The results showed that caregivers had a comparable compromised quality of life as patients as is evident by the comparable scores except for a significant decrease in Psychological health and Social relationships in patients. The caregivers of patients

suffering from COPD for more than a year had higher ZBI scores and had a worse quality of life.

The results of our study are in concordance with a study conducted in Hong Kong community dwellers which showed that depressive and anxiety symptoms were associated with caregiver's burden, although our study assessed amount of burden which was significantly more in caregivers of patients suffering form COPD for a longer duration [3].

Another study done to determine the quality of life of caregivers demonstrated that COPD caused a significant impact on quality of life of caregivers support the finding of our study. The parameter used to assess the QOL of caregiver was SF-36 whereas we relied on WHOQOL bref Scores and ZBI $[15,16]$.

Our study also demonstrated that even the QOL of life of patients is also severely affected and is in agreement with earlier studies which have demonstrated a significant impact as evident by SGRQ and treatment was associated with an improvement in QOL symptoms [3,15-18].

There are certain limitations to our study, firstly this is a cross sectional study and no intervention was given to either the patients or counseling was done of the caregivers. Secondly, the sample size was small and larger sample size involving hospitals in different location all over the country could help to frame out the national data. A longitudinal study done on both the patient as well as the caregiver with some intervention would have been a better study.

To conclude caregivers of patients suffering from COPD for a longer duration had a poor quality of life as is evident by WHO-QOL Bref score and had mild to moderate burden as evident by ZBI scores. The patients as well as the caregivers have a comparable poor quality of life, although patients had slightly higher scores.

\section{References}

1. COPD Statistical Information.

2. Murthy KJR, Sastry JG Economic burden of chronic obstructive pulmonary disease. NCMH Background Papers - Burden of Disease in India.

3. Blumenthal JA, Keefe FJ, Babyak MA, Fenwick CV, Johnson JM, et al. (2009) Caregiver-assisted coping skills for patients with COPD: background, design, and methodological issues for the INSPIRE-II study. Clin Trials 6: 172-184

4. Caregiver

5. Lee E, Lum CM, Xiang YT, Ungvari GS, Tang WK (2010) Psychosocial condition of family caregivers of patients with chronic obstructive pulmonary disease in Hong Kong. East Asian Arch Psychatry 20: 180-185.

6. Jones PW, Quirk FH, Baveystock CM (1991) The St. George's Respiratory Questionnaire. Respir Med 85: 25-31.

7. Jones PW, Quirk FH, Baveystock CM, Littlejohns P (1992) A self-complete measure of health status for chronic airflow limitation. The St. George's Respiratory Questionnaire. Am Rev Respir Dis 145: 1321-1327.

8. Meguro M, Barley EA, Spencer S, Jones PW (2007) Development and validation of an improved COPD-Specific version of the St. George's Respiratory Questionnaire. Chest 132: 456-463.

9. Skevington SM, Lotfy M, O' Connell KA; WHO QOL Group (2004) The World Health Organization's WHOQOL-Bref quality of life assessment: psychometric properties and results of the international field trial. A report from the WHOQOL group. Qual Life Res 13: 299-310.

10. Sainfort F, Becker M, Diamond R (1996) Judgments of quality of life of individuals with severe mental disorders: patient self-report versus provider perspectives. Am J Psychiatry 153: 497-502.

11. Alshubaili AF, Ohaeri JU, Awadalla AW, Mabrouk AA (2008) Family caregiver quality of life in multiple sclerosis among Kuwaitis: a controlled study. BMC Health Serv Res 8: 206. 
Citation: Kumar S, Matreja PS, Gupta AK, Singh A Garg P (2012) To Assess the Quality of Life (QOL) of Caregivers and Patients Suffering from Chronic Obstructive Pulmonary Disease (COPD). J Aller Ther S2:003. doi:10.4172/2155-6121.S2-003

Page 4 of 4

12. Anees M, Hameed F, Mumtaz A, Ibrahim M, Saeed Khan MN (2011) Dialysisrelated factors affecting quality of life in patients on haemodialysis. Iranian $J$ Kidney Dis 5: 9-14.

13. Zarit SH, Reever KE, Bach-Peterson J (1980) Relatives of the impaired elderly: Correlates of feelings of burden. Gerontologist 20: 649-655.

14. Hebert R, Bravo G, Preville M (2000) Reliability, validity and references value of the Zarit Burden Interview for assessing informal caregivers of communitydwelling older persons with dementia. Canadian J Aging 19: 494-507.

15. Pinto RA, Holanda MA, Medeiros MM, Mota RM, Pereira ED (2007)Assessment of the burden of caregiving for patients with chronic obstructive pulmonary disease. Respir Med 101: 2402-2408.

16. Miravitlles M, Molina J, Naberan K, Cots JM, Ros F, et al. (2007) Factors determining the quality of life of patients with COPD in primary care. Ther Adv Respir Dis 1: 85-92.

17. Kaplan A (2010) Effect if tiotropium on quality of life in COPD: a systemic review. Prim Care Respir J 19: 315-325.

18. Menn P, Weber N, Holle R (2010) Health-related quality of life in patients with severe COPD hospitalized for exacerbation-comparing EQ-5D, SF-12 and SGRQ. Health and Quality of life outcomes 8: 39. 